Competing interests None

Provenance and peer review Commissioned; not externally peer reviewed.

Published Online First 20 May 2011

Thorax 2011:66:744-745.

doi:10.1136/thx.2011.160853

\section{REFERENCES}

1. Braun-Fahrlander C, Riedler J, Herz U, et al. Environmental exposure to endotoxin and its relation to asthma in school-age children. $N$ Engl $\mathrm{J} \mathrm{Med}$ 2002;347:869-77

2. Blumer N, Herz U, Wegmann M, et al. Prenatal lipopolysaccharide-exposure prevents allergic sensitization and airway inflammation, but not airway responsiveness in a murine model of experimental asthma. Clin Exp Allergy 2005:35:397-402.

3. Gerhold K, Bluemchen K, Franke A, et al. Exposure to endotoxin and allergen in early life and its effect on allergen sensitization in mice. J Allergy Clin Immunol 2003:112:389-96.
4. Eisenbarth SC, Piggott DA, Huleatt JW, et al. Lipopolysaccharide-enhanced, toll-like receptor 4-dependent T helper cell type 2 responses to inhaled antigen. J Exp Med 2002;196:1645-51.

5. Debarry J, Garn H, Hanuszkiewicz A, et al. Acinetobacter Iwoffii and Lactococcus lactis strains isolated from farm cowsheds possess strong allergy-protective properties. J Allergy Clin Immunol 2007:119:1514-21.

6. Blumer N, Sel S, Virna S, et al. Perinatal maternal application of Lactobacillus rhamnosus GG suppresses allergic airway inflammation in mouse offspring. Clin Exp Allergy 2007;37:348-57.

7. Vogel K, Blumer N, Korthals M, et al. Animal shed Bacillus licheniformis spores possess allergy-protective as well as inflammatory properties. J Allergy Clin Immunol 2008;122:307-12, 312.e1-8.

8. Peters $\mathbf{M}$, Kauth $\mathbf{M}$, Scherner 0 , et al Arabinogalactan isolated from cowshed dust extract protects mice from allergic airway inflammation and sensitization. J Allergy Clin Immunol 2010:126:648-56, e1-4.

9. Patel M, Xu D, Kewin P, et al. TLR2 agonist ameliorates established allergic airway inflammation by promoting Th1 response and not via regulatory $T$ cells. J Immunol 2005; 174:7558-63

10. Sel S, Wegmann M, Sel S, et al. Immunomodulatory effects of viral TLR ligands on experimental asthma depend on the additive effects of IL-12 and IL-10. J Immunol 2007;178:7805-13.

11. Kim YS, Kwon KS, Kim DK, et al. Inhibition of murine allergic airway disease by Bordetella pertussis. Immunology 2004;112:624-30.

12. Lauener RP, Birchler T, Adamski J, et al, ALEX study group. Expression of CD14 and Toll-like receptor 2 in farmers' and non-farmers' children. Lancet 2002;360:465-6.

13. Ege MJ, Bieli C, Frei R, et al, Parsifal Study team. Prenatal farm exposure is related to the expression of receptors of the innate immunity and to atopic sensitization in school-age children. J Allergy Clin Immunol 2006;117:817-23.

14. Nembrini C, Sichelstiel A, Kisielow J, et al. Bacterial-induced protection against allergic inflammation through a multicomponent immunregulatory mechanism. Thorax 2011:66:755-63.

\title{
Cardiovascular mechanisms of death in severe COPD exacerbation: time to think and act beyond guidelines
}

\author{
Leonardo M Fabbri, ${ }^{1}$ Bianca Beghé, \\ Alvar Agusti
}

Three important studies on acute exacerbations of chronic obstructive pulmonary disease (ECOPD)have been published in Thorax. Two of them, by Chang et al ${ }^{1}$ (see page 764) and Hoiset et al (see page 775), show the importance of the cardiac biomarkers troponin $\mathrm{T}$ and NT-BNP (Nterminal pro-B-type natriuretic peptide) as strong predictors of the increased risk of death of patients hospitalised because of ECOPD. ${ }^{12}$ The third, by Maclay et $a l^{3}$ (see page 769), provides evidence that patients with stable chronic obstructive

\footnotetext{
${ }^{1}$ Section of Respiratory Diseases, Department of Oncology Haematology and Respiratory Diseases, University of Modena and Reggio Emilia, Policlinico di Modena, Italy; ${ }^{2}$ Thorax Institute, Hospital Clínic, IDIBAPS, Universitat Pompeu Fabra, Centro de Investigación Biomédica en Red de Enfermedades Respiratorias (CIBERES), Barcelona, Spain
}

Correspondence to Leonardo M Fabbri, Section of Respiratory Diseases, Department of Oncology Haematology and Respiratory Diseases, University of Modena and Reggio Emilia, Policlinico di Modena, Italy; leonardo.fabbri@unimore.it pulmonary disease (COPD) have increased circulating platelet-monocyte aggregates-a potential specific pathogenic mechanism of atherosclerosis. These aggregates further increase during exacerbations, suggesting a plausible biological mechanism to explain the increased cardiovascular risk seen in ECOPD. Taken together, these studies confirm the view that ECOPD episodes requiring hospitalisation must be considered very severe events in the natural course of the disease because they are associated with such important outcomes as increased risk of mortality, reduced health status, impaired lung function, muscle weakness, and cardiopulmonary complications. ${ }^{4}$ The studies also suggest that the increased risk of death is often due to acute cardiovascular involvement, and they highlight the limitations of the current definition of ECOPD and the need to move towards a more comprehensive definition, diagnostic approach and treatment.

\section{RISK OF DEATH AND EXACERBATIONS OF} COPD

Several previous studies have clearly established that episodes of ECOPD are a major driver of mortality in this disease, especially during and immediately after the acute event. (The long-term effects are discussed in next paragraph.) For instance, in a cohort of 1016 patients hospitalised because of ECOPD with hypercarbia $\left(\mathrm{PaCO}_{2} \geq 50 \mathrm{~mm}\right.$ $\mathrm{Hg})$, Connors et al ${ }^{5}$ reported that mortality was $11 \%$ in hospital, and $20 \%, 33 \%, 43 \%$ and $49 \%$, respectively, at 60 days, 180 days, 1 year, and 2 years after discharge. More recently, Chang et $a l^{6}$ reported that mortality during the first 30 days after hospitalisation varied between $2 \%$ and $21 \%$ according to the CURB65 score. CURB65 is a composite index based on confusion, blood urea, respiratory rate, blood pressure and age that was developed to predict mortality risk in community-acquired pneumonia. ${ }^{6}$ Together these studies demonstrate that mortality during and immediately after hospitalisation for ECOPD is remarkably high.

Episodes of ECOPD also affect longterm mortality. This is best illustrated by the study of Soler-Cataluña et al, ${ }^{7}$ who followed a cohort of 304 patients with COPD for 5 years and found that mortality increased in direct proportion to the frequency of ECOPD; that is, patients with frequent episodes (three or more) had the greatest mortality risk (HR 4.13; $95 \%$ CI 1.80 to 9.41 ). In agreement with Connors et al, ${ }^{5}$ Soler-Cataluña et al also found that arterial hypercarbia was an independent marker of poor prognosis (HR 1.07; 95\% CI 1.02 to 1.12). 


\section{CARDIOVASCULAR DISEASE AND EXACERBATIONS OF COPD}

Cardiovascular disease (CVD) is an important cause of mortality in COPD, ${ }^{8}$ and, as recently shown by Donaldson et $a l^{9}$ the risk of acute vascular events appears to be particularly high during episodes of ECOPD. After analysing data from 25857 patients with COPD who were entered in the Health Improvement Network database over a 2-year period, Donaldson et al reported that the risk of myocardial infarction 1-5 days after an ECOPD episode increased 2.3-fold (95\% CI 1.1 to $4.7 ; p=0.03$ ), and that the risk of stroke 1-49 days after ECOPD increased 1.3-fold (95\% CI 1.0 to $1.6 ; p=0.05){ }^{9}$ Furthermore, a 2009 retrospective postmortem study of patients who died within $24 \mathrm{~h}$ of hospitalisation because of ECOPD showed that cardiac failure and thromboembolism were the principal causes of death. ${ }^{10}$

The mechanisms linking COPD and CVD are unclear, but the presence of lowgrade chronic systemic inflammation is likely to be an important one. ${ }^{11-13}$ Systemic inflammation increases during ECOPD, ${ }^{14} 15$ providing a potential mechanism to explain the increased risk of vascular events associated with ECOPD. ${ }^{9}$ The three studies published in this issue provide new information that can contribute to a better understanding of the relationship between ECOPD, inflammation and cardiovascular events. The first two studies ${ }^{12}$ found that the plasma levels of the cardiac biomarkers NTproBNP and troponin Twere abnormal in a significant number of patients hospitalised because of ECOPD, and that both markers predicted mortality ${ }^{1} 2$ even after adjusting for other predictors of mortality such as $\mathrm{PaCO}_{2}$ or CURB65 score. ${ }^{1}$ The third study found that, compared with healthy controls, patients with COPD had increased circulating platelet-monocyte aggregates, which were further increased during ECOPD. ${ }^{3}$ Together these findings suggest that cardiovascular involvement in ECOPD may be an important determinant of prognosis and death, opening new avenues for research of novel diagnostic and therapeutic strategies.

\section{LIMITATIONS OF THE CURRENT DEFINITION OF EXACERBATION OF COPD} Maclay et $a l^{3}$ studied only patients with ECOPD, excluding those with acute heart failure, pneumonia or pulmonary embolism. However, Chang et $a l^{1}$ and Hoiset et $a l^{2}$ do not provide detailed criteria of inclusion and exclusion, nor the full range of examinations performed to exclude alternative or concomitant causes of an increase in respiratory symptoms that may mimic an episode of ECOPD.

Unfortunately, the current definition of ECOPD is still very much descriptive and clinical. Episodes of ECOPD are defined as acute events characterised by a change in the patient's baseline dyspnoea, cough, and/or sputum that is beyond normal dayto-day variations; in a patient with underlying COPD, these events may warrant a change in medication. ${ }^{16-18}$ However, while this definition may be useful in epidemiologic studies, ${ }^{19}$ it is often of limited use in the clinical setting. It is suggested that more than half of ECOPD episodes are caused by viral and bacterial infections or pollutants. ${ }^{16-18}$ These exacerbations are most likely associated with the three cardinal respiratory symptoms, increased sputum, purulent sputum and dyspnoea. In these cases, dyspnoea most likely worsens because of increased inflammation of the airways and the lung due to the infection or pollutant. However, patients with COPD often have several concomitant disorders. Therefore acute inflammation of the airways and the lung may not only worsen dyspnoea by affecting the respiratory system, but may also have systemic effects because of acute systemic inflammation and thus cause dyspnoea by affecting the cardiovascular or metabolic system. Moreover, other conditions, such as pulmonary embolism, acute cardiac failure, pneumonia, pneumothorax and anaemia, can mimic ECOPD by precipitating respiratory symptoms, particularly dyspnoea. Considering this complexity of causes, we suggest that the term 'exacerbations of COPD' be changed to 'exacerbations of respiratory symptoms in patients with COPD'. For the same reason, there is great interest in identifying biomarkers that can facilitate a more precise diagnosis of ECOPD and its aetiology. The three studies published in this issue suggest that serum biomarkers such as troponin T and NT-BNP may not only identify patients at increased risk of death but may also help to determine the relative role of extra-respiratory events, such as acute heart failure or thromboembolism, and that of other causes of acute dyspnoea in patients with COPD.

\section{NEED FOR A MORE COMPREHENSIVE DIAGNOSTIC AND THERAPEUTIC APPROACH}

These three articles ${ }^{1-3}$ extensively discuss the mechanisms underlying the increased levels of cardiac biomarkers and platelet activation during ECOPD, as well as their clinical significance. The increase in troponin $\mathrm{T}$ and NT-BNP may be due to several different causes, including systemic inflammation, respiratory failure, coronary artery disease, left ventricular dysfunction, right ventricular pressure overload due to pulmonary hypertension, or pulmonary thromboembolism. However, platelet activation might not only be due to systemic inflammation but also to other concomitant chronic conditions such as rheumatoid arthritis or diabetes, or acute conditions such as hypoxaemia, tachycardia and hyperglycemia, all predictors of poor outcome in patients with ECOPD. 48

Guidelines provide clear evidence-based recommendations on how to diagnose and treat respiratory abnormalities during ECOPD episodes, but provide little direction on how to deal with concomitant abnormalities in patients with COPD. Considering the high risk of cardiovascular complications and death from ECOPD, we agree with the authors of the three studies discussed here that, while awaiting the generation of the necessary scientific evidence, patients hospitalised because of ECOPD should be carefully examined for the relevant biomarkers and for any concomitant abnormality that may call for specific therapy. This in line with the recent editorial of FitzGerald ${ }^{20}$ and comment by the Editors of Thorax ${ }^{21}$ who recommend replacing the term 'exacerbations' with the term 'lung attacks' to emphasise their severity, dramatic consequences, and need for more aggressive, comprehensive and prolonged treatment.

Competing interests $A A$ has received consultancy fees from Almirall, Esteve, AstraZeneca, Boehringer Ingelheim, Chiesi Farmaceutici, GlaxoSmithKline, Novartis, Nycomed; payment for lectures and support for travel expenses from AstraZeneca, Boehringer Ingelheim, Chiesi Farmaceutici, GlaxoSmithKline, Novartis, Nycomed; and AA's institution has received grants from Almirall, GlaxoSmithKline, and Nycomed. LMF has received consultancy fees from Actelion, AstraZeneca, Boehringer Ingelheim, Chiesi Farmaceutici, GlaxoSmithKline, Elevation Pharmaceuticals, Merck Sharp \& Dohme, Novartis, Nycomed, Pearl Therapeutics, Roche and Sigma-Tau; payment for lectures and support for travel expenses from AstraZeneca, Boehringer Ingelheim, Chiesi Farmaceutici, Euromediform SrL, GlaxoSmithKline, German Centre for Lung Research, Merck Sharp \& Dohme, Menarini, Mundipharma International, Novartis, Nycomed, TEVA Pharmaceuticals, Pfizer, and Sigma-Tau; and LMF's institution has received grants from Boehringer Ingelheim, Chiesi Farmaceutici, GlaxoSmithKline, Italian Ministry of Health, Italian Ministry for University and Research, Merck Sharp \& Dohme, Nycomed, and Sigma-Tau. BB has received payment for lectures and support for travel expenses from AstraZeneca, Chiesi Farmaceutici, Menarini, Nycomed; payment for development of educational presentations from Nycomed. 
Contributors LMF, BB and AA wrote one of the three parts of the manuscript, LMF put them together, and then $L M F, B B$ and $A A$ discussed and agreed on the final manuscript.

Provenance and peer review Commissioned; internally peer reviewed.

Published Online First 8 June 2011

Thorax 2011:66:745-747.

doi:10.1136/thoraxjnl-2011-200406

\section{REFERENCES}

1. Chang CL, Robinson SC, Mills GD, et al. Biochemical markers of cardiac dysfunction predict mortality in acute exacerbations of COPD. Thorax 2011;66:764-8.

2. Hoiseth AD, Neukam A, Karlsson D, et al. Elevated high-sensitivity cardiac troponin $T$ is associated with increased mortality after acute exacerbation of chronic obstructive pulmonary disease. Thorax 2011;66:775-81.

3. Maclay JD, McAllister DA, Johnstone $S$, et al Increased platelet activation in patients with stable and acute exacerbations of COPD. Thorax 2011;66:769-74.

4. Chenna PR, Mannino DM. Outcomes of severe COPD exacerbations requiring hospitalization. Semin Respir Crit Care Med 2010;31:286-94.

5. Connors AF Jr, Dawson NV, Thomas C, et al. Outcomes following acute exacerbation of severe chronic obstructive lung disease. The SUPPORT investigators (Study to Understand Prognoses and
Preferences for Outcomes and Risks of Treatments) Am J Respir Crit Care Med 1996;154(4 Pt 1):959-67.

6. Chang CL, Sullivan GD, Karalus NC, et al. Predicting early mortality in acute exacerbation of chronic obstructive pulmonary disease using the CURB65 score. Respirology 2011;16:146-51. doi:10.1111/ j.1440-1843.2010.01866.x.

7. Soler-Cataluña JJ, Martinez-Garcia MA, Roman Sanchez P, et al. Severe acute exacerbations and mortality in patients with chronic obstructive pulmonary disease. Thorax 2005;60:925-31.

8. Sin DD, Anthonisen NR, Soriano JB, et al. Mortality in COPD: role of comorbidities. Eur Respir $J$ 2006;28:1245-57

9. Donaldson GC, Hurst JR, Smith CJ, et al. Increased risk of myocardial infarction and stroke following exacerbation of COPD. Chest 2010;137:1091-7.

10. Zvezdin B, Milutinov S, Kojicic $M$, et al. A postmortem analysis of major causes of early death in patients hospitalized with COPD exacerbation. Chest 2009;136:376-80

11. Sin DD, Man SF. Why are patients with chronic obstructive pulmonary disease at increased risk of cardiovascular diseases? The potential role of systemic inflammation in chronic obstructive pulmonary disease. Circulation 2003;107:1514-19.

12. Fabbri LM, Rabe KF. From COPD to chronic systemic inflammatory syndrome? Lancet 2007;370:797-9.

13. Agusti A. Systemic effects of chronic obstructive pulmonary disease: what we know and what we don't know (but should). Proc Am Thorac Soc 2007:4:522-5.
14. Wedzicha JA, Seemungal TA, MacCallum PK, et al. Acute exacerbations of chronic obstructive pulmonary disease are accompanied by elevations of plasma fibrinogen and serum IL-6 levels. Thromb Haemost 2000;84:210-15.

15. Drost EM, Skwarski KM, Sauleda J, et al. Oxidative stress and airway inflammation in severe exacerbations of COPD. Thorax 2005;60:293-300.

16. Wedzicha JA, Seemungal TA. COPD exacerbations: defining their cause and prevention. Lancet 2007;370:786-96.

17. Global Initiative for Chronic Obstructive Lung Disease. Global strategy for the diagnosis, management, and prevention of chronic obstructive pulmonary disease. 2009. http://www.goldcopd.org. Access date: 27 April 2011.

18. National Institute for Health and Clinical Excellence. Chronic obstructive pulmonary disease: management of chronic obstructive pulmonary disease in adults in primary and secondary care. National Clinical Guideline Centre, 2010. http://guidance.nice. org.uk/CG101/Guidance/pdf/English. Access date: 27 April 2011.

19. Hurst JR, Vestbo J, Anzueto A, et al. Susceptibility to exacerbation in chronic obstructive pulmonary disease. N Engl J Med 2010;363:1128-38.

20. FitzGerald JM. Targeting lung attacks. Thorax 2011 May:66(5):365-6.

21. Bush A, Pavord I. Following Nero: fiddle while Rome burns, or is it there a better way? Thorax 2011;66:367.

\section{Call for papers}

The Editorial Board would like us to have a North American-ATS themed issue in April 2012, for distribution at the ATS in May. We are therefore inviting manuscripts which either originate from North America, or relate to work which will be presented at the ATS meeting. All manuscripts will of course be rigorously peer reviewed in the usual way. Deadline for consideration 1 December 2011; please mention this call in the cover letter. The Editors would be happy to discuss any potential submissions. 